EJMS

26,1

Received 16 January 2021

Revised 30 January 2021

10 April 2021

Accepted 3 May 2021

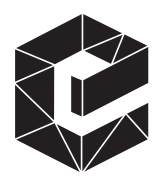

European Journal of Management

\section{Budgetary restrictions and ethical behaviours in a hospital context - evidence from general surgeons}

\author{
Cristina Piedade Silva and Rita Martins de Sousa \\ ISEG, Lisbon School of Economics and Management, Universidade de Lisboa, Portugal
}

\begin{abstract}
Purpose - The purpose of this paper is to study how budgetary constraints can have ethical implications on patient treatment options.

Design/methodology/approach - By applying a qualitative methodological approach (interviews) and participant observation, this paper studies the behaviour of surgeons in scenarios of financial restriction.

Findings - The empirical findings show that despite the conflict between the economy and the leges artis, surgeons maintain the ethical and deontological principles of their profession with fair rules of orientation.

Practical implications - The importance of this study can be realised by its continuity. One of the authors is already implicated on a wider research to investigate the influence of the economic scarcity of resources on general surgeons' ethical behaviours.

Social implications - This paper is a contribution to understanding the rules that restrain the activities of surgeons. Politicians sometimes do not have a full understanding of the pressures that the medical profession faces in their day-to-day activities. Currently, with the addition of problems relate to COVID-19, politicians and populations seem to better understand the importance of the Serviço Nacional de Saúde (SNS), This paper hopes that this understanding will be not only a conjectural moment.

Originality/value - In conjunction with the economic recession that began in the first decade of this century, health institutions have long faced budgetary constraints that condition their material and human resources and correspondingly shape the scope of health professional activities. Until now, it has not been studied the impact of economic crises on the ethical behaviour of Portuguese surgeons. Therefore, this research is a first step and a useful contribution to understanding the rules that can restrain (or not) the ethical conduct of these health professionals.
\end{abstract}

Keywords Ethics, Health, Human resources management, Budget restrictions

Paper type Research paper

\section{Introduction}

Throughout the world, medical specialists focus on the issue of how the general economy affects their activities, particularly in terms of the ethical implications and consequences that eventual budgetary constraints may have on their patient treatment options.

(C) Cristina Piedade Silva and Rita Martins de Sousa. Published in European Journal of Management Studies. Published by Emerald Publishing Limited. This article is published under the Creative Commons Attribution (CC BY 4.0) licence. Anyone may reproduce, distribute, translate and create derivative works of this article (for both commercial and non-commercial purposes), subject to full attribution to the original publication and authors. The full terms of this licence maybe seen at http://creativecommons.org/licences/by/4.0/legalcode

The authors are grateful to the comments and suggestions of two anonymous referees, as also to the support of FCT, I.P., the Portuguese national funding agency for science, research and technology, under Project UIDB/04521/2020. 
Medical ethics, described by the medical dictionary (Manuila et al., 2000) as medical deontology, represents that set of obligations inherent to medical practice. Surgeons (who are also human beings and human resources) should guide their choices through ethics as if they were responding to the same question posed at each moment in their lives, namely, "how should I act?", which is the well-known Kantian question that advocates respect and duty towards all others (Santos, 2012).

In this context and based on the deontological Portuguese code of medicine, there are certain questions that challenge the practice of these obligations. Thus, the starting point for this research is to understand if best practices remain under conditions of economic restraint/ economic crisis; i.e. do Portuguese general surgeons ("based on the fundamental ethical principles that constitute the pillars of the medical profession") maintain good practices regardless of the restrictions to which they have been subjected to since the crisis of 2011-2014? The following sub-questions aim to deepen these behavioural variables and their effects:

Q1. How do these constraints interfere with the efficiency of their choices?

Q2. Do general surgeons use their right of the conscientious clause when these restrictions conflict with their conscience?

Q3. Do surgeons communicate to the Portuguese College of Physicians (Ordem dos Médicos) any irregular situation caused by these constraints and any possible consequence involving inefficient attitudes or third-party violations of the rules of conduct?

Q4. Are there any differences in these rules of restraint between public and private institutions?

Q5. Do human resource departments or ethics committees influence their decisionmaking?

In European countries, evidence of the impact of the economic crisis on doctors is still scarce (Rego et al., 2017). Although research in the field of sociology of health provides conditions for reflection on the impacts of the economic crisis on doctors, and because "the increase in the legal power attributed by political power to hospital managers affects medical autonomy", doctors are central figures in the functioning of public hospitals and are "responsible for defining and implementing health-care provision" (Correia, 2012); however, the consequences that this brings to their behaviour have not yet been examined. Therefore, this research is an important step to understanding this connection.

After this introduction, the remainder of the paper is organised as follows. In Section 2, we introduce a brief theoretical presentation is presented about the relation between ethics and human resources management. In Section 3, we explain the consequences of the financial crisis in the Portuguese health system, especially in regard to surgeons. In Section 4, we explain the methodological options and we analyse the results. Section 5 concludes.

\section{Ethics and human resources management}

Amongst the leading features of any organisation are the ways in which people demonstrate higher or lower standards of ethical behaviour depending on the organisational context; thus, all managers need to play active roles in guiding employees through their social responsibilities (Torrington et al., 2009). Consequently, the value of ethics also requires interpretation, as people are driven by moral and altruistic purposes, trust and values ("right" versus "wrong"); however, these values can sometimes be in conflict and generate ethical dilemmas. Deontology evaluates the ethicality of behaviour based on duties, 
EJMS

26,1

18

obligations, principles and respect for human beings - motivation is more important than consequences - leading to the codes of conduct for many professions.

Ethical dilemmas occur in the workplace; as such, workers need information and should be enabled to ask about and easily access the code of conduct of their organisation, in addition to taking the individual's own values into account. An ethical consciousness leads to ethical judgements that drive ethical action without overlooking how the decisions of individuals concerning what is ethically correct intrinsically interlink with what others think. However, this factor declines in relevance for individuals who hold post-conventional principles, resist external pressures and, as leaders, strengthen the ethical climate (Kohlberg, 1969).

Regarding ethical problems arising from the misuse of organisational resources, Treviño \& Nelson (2011) declare individuals to be responsible for the good and appropriate utilisation of corporate resources, which includes a firm's finances and reputation. Thus, employees must honour the organisations they represent by correctly using their resources. Employees who report abusive behaviours by their peers undertake actions perceived by researchers as requiring courage, especially in difficult cases that are susceptible to posing serious organisational risks, whether financial or otherwise.

Jennings (2006) explains how the phenomenon of silence towards accusations arises from a lack of fit. Consequently, the feeling of not belonging to a team encourages a culture of fear that stems from group thinking and the inability of human beings to identify what is wrong in the midst of a group that fails to see clearly. The author notes that in 2005 and 2006 , only $50 \%$ of respondents reported unlawful or unethical conduct by their peers. The literature portrays these factors as enemies of an ethical culture that are capable of boosting the likelihood of ethical collapse. Stronger organisational cultures (with their formal and informal systems strongly aligned to supporting ethical behaviours) enhance the natural processes of employee acculturation or socialisation. Therefore, employees end up behaving in line with actions that are observed to fit into the respective organisational context, which is in line with the expected ethical culture (Treviño \& Nelson, 2011). These authors also explain that for communication to flow, human resource departments need to be accessible to employees and organise all formal and informal channels to broadcast the ethical message, beginning with the recruitment brochures. It is also relevant to train both new and existing employees by integrating top management and applying models such as ethics games so that people feel open to anonymously reporting or questioning all types of issues. Additionally, as human beings tend to avoid punishment and engage in actions, which receive rewards, reward (as a motivational factor for ethical behaviour) and punishment systems must be communicated widely. The authors also explain how the obligations inherent to each duty may lead to either ethical or unethical behaviours. The pressure applied by the demands (time and formalities) of each assignment can lead to conflicting responses to the ethical behaviours expected; therefore, the origins of these conflicts require exploration. On the other hand, reporting poor peer behaviour, even though it is a difficult act, constitutes a mandatory task for any assignment that is incorporated into the code of conduct and is furthermore presented as a means of encouraging ethical behaviours (Treviño \& Nelson, 2011).

Greenwood (2002) concludes that the minimum standard for approaching and evaluating human resources management is that people and organisations should treat individuals with respect without ever interfering with their freedoms.

\section{The troika, health and deontology}

Barros \& Nunes (2009) emphasise that the presence of social sciences in the field of health is a way to promote multi-disciplinary work in regard to understanding the dynamics of 
chronic conditions because of the multi-cultural exposure of societies, as doing so enables the identification of stress factors and the development of action strategies for physical, psychic and cultural factors, as well as the promotion of humanisation in patient care and work relationships.

This is one of the reasons that encouraged us to go to the field and examine the feelings of the Portuguese general surgeons who have been facing economic constraints for more than a decade now. Carapinheiro (2010) underlines that:

$[\ldots]$ special emphasis is placed on the growth of health expenses, the reduction of costs and the improvement of the efficiency of the production of healthcare, the improvement of the quality of the services provided and the discussion on the financing regimes that make them feasible (p. 59).

The financial crisis of 2008 and the consequent austerity policies that spread across Europe have raised ethical challenges that have impacts on the public health framework. According to Brall et al. (2016), countries such as Portugal have accepted and suffered from the implementation of ethically dubious Troika austerity measures, even while most European countries have only changed their contribution levels and health costs. The wages of professionals have been frozen or reduced, leading to emigration or migration to private institutions; admission rates have nevertheless increased, which has also led to many Portuguese Public Health Service Serviço Nacional de Saúde (SNS) users choosing private institutions; waiting lists have lengthened; and negotiations with the suppliers of medicines and medical technology have led to decreases in prices, thereby generating a negative impact on innovation and consequently on economic growth. In summary, primary care has been subject to a low-cost model, with health becoming dehumanised. This adherence by the public health sector to market values neglects the patient-centered approach and respect for patient dignity and individuality, regardless of their economic or social condition. Furthermore, both infant mortality rates and the number of human immunodeficiency virus-related deaths have risen, and the overall mortality rate has also increased due to a rise in the prevalence of the influenza virus resulting from the poor quality of domestic heating and housing across the country. These authors appeal for the confirmation of both this reduction in resources and the deviation towards private health-care as, to be ethically acceptable from the capacity approach point of view, anything that decreases health literacy is prima facie morally unfavourable and the lack of health-care promotion is seen to be criticism (Brall et al., 2016).

Sakellarides et al. (2014) add that the 2014 Adjustment Programme for Portugal included increasing hospital treatment access charges; generic medicine price limitations (with $60 \%$ doses of the original product) and incentives for their consumption; a logistics centre for the SNS; hospital operating cost reductions of $50 \%$ in 2012; an increase in professional mobility; and a $10 \%$ reduction in overtime expenditures in each of the following two years. In addition, the "commitment law" limited new procurement, the 13th- and 14th-month wage payments were abolished for all health workers, career progression was frozen and retirement benefits were reduced. However, the aforementioned authors fail to identify the consequences of these budget cuts, wage reductions and changes in working conditions to the ongoing health-care process, even while advocating for greater attention to the contribution that health care brings to the economy.

Deontology, deon (from the Greek, "what must be done") is, according to Neves (2016), an ethic of absolute rules, including the obligations of "do's" and "do nots" and is very much centered on individual action. The moral decision complexity problem may arise in any technical profession, including specialist fields, where there is never enough preparation for weighing decisions in cases where the choices range between black and dark grey. Hortal (2004) (apud Neves, 2016) emphasises that deontology guides the actions of individuals 
EJMS

26,1

20

towards good whenever they work, which incorporates facets such as thorough professionalism, humanity and social sense. In turn, Santos (2012) states that "deontology is considered a procedural ethics". This author aligns with Rawls (2013) theory of justice (2013) and states that to act ethically and within a deontological ethical framework involves achieving the role of justice as a duty or a moral law, with "good" depending on "fair" and standing independent of the consequences of those actions.

According to regulation (No. 707/2016 of the Diário da República No. 139/2016), the Portuguese College of Physicians code of ethics consists of a set of ethical norms that guide human relations in the practice of medicine, which includes duties such as respect for the right to health, abstention from unjustified practices, the protection of society, nondiscrimination, the provision of both the best care and acts recognised by the leges artis. Such practices are expected to be carried out within the scope of the daily surgeon's routine.

\section{Methodology}

This research was based on interviews with general surgeons and participant observations examined within the scope of one of the author's professional activities, in accordance with the autoethnography model.

The sample includes 31 general surgeons. It is a randomised sample based on the surgeons that immediately agreed to be interviewed and participate on the study. They represent most on the public hospitals and on the private group. They were asked to take part of this research during the participant observation. The surgeons were of both genders who range in age from 37 to 70 years old and work in several SNS hospitals in the north, central and southern regions of Portugal. Only one respondent works exclusively in private medicine, while three have recently moved from public to private hospitals for different reasons. In total, 14 of these physicians practice both public and private medicine; 11 work only in the public system, with 3 working in public-private partnerships (PPPs). Two physicians very recently left the public sector for the private sector, while the remainder has been exclusively working in the private sector for the past 10 years. The surgeons all have at least one and a maximum of 33 years of practice, in addition to their six-year residencies. In terms of professional category, these surgeons work as assistants, graduate assistants and heads or directors of departments. Selection took place independent of graduation, gender or age. All the interviewees expressed great enthusiasm and willingness regarding participation in the study.

Data collection involved semi-directed interviews (Table A2 in Appendix), open-ended questions and participant observation. The interviews took place in hospital centres, hospital public entity businesses, PPPs and a nationally owned private hospital group. The interviews were carried out within the scope of the researcher's professional activities and following an initial approach of the doctors, either personally, i.e. in the hospital where he/ she works or by phone, including clarification regarding the objectives and duration of the interview. The interviewees were also informed of their anonymity.

Given that most surgeons are also enrolled in the private practice of medicine, the same questions were extended to the scope of their private practice when applicable. The interviews were held between $23^{\text {rd }}$ February 2018 and $22^{\text {nd }}$ March 2018 and lasted an average of $1 \mathrm{~h}$; at the end of the interview, almost every respondent sought out an informal conversation on the same subject, with some requesting that details helpful for identifying them in the medical community be ignored. For this reason, the sample is not gender-specific and hospital identification details are also omitted. Following content analysis, the relevant quotations were selected. 
These interviews were combined with participant observations obtained by maintaining a physical presence at many surgeries performed in hospital operating theatres, which are places where expensive materials are used daily and where professionals often receive advice about choosing cheaper materials. The fieldwork and participant observations allowed for the perception of special routines and events - regardless of whether they were predictable - as well as adverse situations (such as emergencies) and the gauging of the choices made by surgeons when faced with economic decision-making in the surgical context of treating abdominal wall hernias.

Many of the most relevant medicine-related articles on ethics and economics were identified online in specialised medical journals and subsequently made available by their general surgeon authors. This included documentation research, including relevant data from organization of economic co-operation and development countries on the share of the gross domestic product applied to health care, public opinion findings on health care-related issues and health care purchasing power, the Hippocratic oath and the Portuguese College of Physicians code of ethics.

The MAXQDA13 programme was applied to analyse categories and subcategories (Bardin, 2003) (Table A1 in Appendix). These categories were organised according the objectives of the research, namely, to understand if Portuguese general surgeons maintain good practices in spite of the restrictions to which they have been subjected to since the crisis of 2011-2014 and the discussed theoretical framework.

Therefore, we organised these categories into seven groups. The first is the identification of the surgeon by age, experience and the service focus of the employee (public or private) because these indicators can explain (or not) some medical decisions. The second category is concerned with the vision of the Portuguese Public Health Service, to understand how the public administration, manages the health service and if this has consequences also in medical decisions. The third category links financial restrictions with ethical decision-making. After the analysis of organisational background, the fourth category associates individual ethics with the code of deontology and the fifth one connects ethical problems with the report of infractions. This report is very important to signalised and avoid, if possible, unethical practices. The sixth category-related context and individual ethics because as we examined in the theoretical framework an ethical decision-making process can be explained by the link between organisational context and individual morality. The last category is concerned with the influence of bodies such as human resource management and ethics committees on ethical decision-making. Considering these categories, we can understand the power of different dimensions in an ethical decision take by general surgeons in a hospital context.

\subsection{Results}

To summarise and better understand the results, we considered the main results for each category and subcategories. The main results are not in a table. To protect the identity of interviewees, all the names are presented with $\mathrm{E}$ and numbers. Interviews dates are also mentioned:

Category - vision of the Public Health Service IDENTIFICATION OF VALUES - 21 responses similar to the following:

I identify myself [...] it is a pity that this is, in reality, a list of words that demonstrate a lot but, unfortunately, that is not the reality. E1 (26/02/2018)

\section{HEALTH NATIONAL SERVICE AS AN INDUSTRY - 20 responses similar to the following:}

It behaves like an industry in a very subtle way, inasmuch as managers apply too many calculations and bills and forget that hospitals are not really industries [...] I think the voracity of making, between quotes, profitable hospitals, makes hospitals poor and [...] resources [...] 
EJMS

26,1

22

sacrifice elements and aspects and purchases that are necessary, anyway [...] I think that managers forget that they are managing hospitals and not factories [. . . E3 (14/03/2018).

\section{Category - Budget restrictions and good practices}

THE IMPACT OF THE CRISIS - 27 responses similar to the following: "I felt a lot and I still do. .."

In addition, "hospital without own financing", "reduction of HR and beds", "salary", "material, exams, payment to suppliers", "hospital clothes", "repair of materials and equipment", "in the hospitality sector", "introduction of new techniques", "limitations of vacancies and cancellations of patients", "team spirit", "decreased operating volume", "patient accessibility", "lack of quality", "training", "demotivation”, "medical attention" and "disinvestment in treatments".

\section{CONSTRAINTS AND GOOD PRACTICES - 24 responses confirm that they were affected}

"Lowest cost option", "lack of means", "lack of incentives", "lack of HR", "postponements and cancellations of surgeries", "restriction of professional freedom", "non-practice of the state of the art with the loss for the patient", "salary cuts", "motivation", "errors due to physical and mental exhaustion", "lack of material and equipment repair", "poor attention and incorrect treatment of the patient", "limitation on the medical industry support for training" and "increasing the waiting list".

\section{RESPONSIBILITY FOR MANAGING THE BUDGET - 25 answers similar to the following:}

We have a duty and morale, in terms of morals, a morality to make the right choices, as if all the money came from our own pocket [ . . . E6 (26/02/2018).

\section{EFFICIENCY AND RESOURCES - 29 responses similar to the following:}

There was a reduction in staff at the emergency department, due to burnout [ . . ] in this way, the money undoubtedly affected the services provided E3 (26/02/2018).

And this interferes in treating patients "yes. Patients could have been better treated if we had access to better materials for that purpose [...] provided" E16 (14/03/2018).

CANCELLATION/POSTPONEMENT OF SURGERIES - 22 answers similar to the following:

I have already changed the treatment initially scheduled for a patient due to lack of resources, and I have also cancelled surgeries due to lack of resources. E11 (08/03/2018).

\section{Category - Individual ethics and deontology}

\section{BUDGET RESTRICTIONS AND LEGES ARTIS - 24 affirmative answers}

CONFLICT EXAMPLES "not doing the best for the patient", "I want to do things and they do not let me", "they force us to treat patients with what we have", "they choose the cheapest", "even so, the patient is operated on, even knowing that it is not the best, but [...]", "decisions made too late", "huge waiting list with an impact on the patient's quality of life", "if I do not have the materials indicated, I cannot be absolutely correct in the treatment to be provided" and "because we are not free to use or do what we think it is the best for the patient".

CURTAIL THE FREEDOM OF CLINICAL/ETHICAL JUDGEMENT:

Yes -7 answers.

No- 22 answers.

Some answers are similar to the following: 
It can influence, but it won't limit, because if I think that a procedure or a technique or some system has to be applied to a patient, and if I don't have the means available, I have to go to the last to get those means. E6 (26/02/2018).

\section{ECONOMIC RESTRICTIONS AND CONSCIENTIOUS OBJECTIONS. 19 negative responses. 12 answers similar to the following:}

Yes, I have already refused to treat patients, and I have had situations in which I have not treated patients in the past, because I believed that all safety conditions were not met.

\section{REFERRAL DUE TO LACK OF RESOURCES - 22 positive answers}

We refer patients because we think that the best possible treatment is not within reach (pause) [. . . ] technically. E12 (12/03/2018).

\section{Category - Individual intervention for the common good}

COMMUNICATION OF INFRACTIONS - Positive: only 4.

Why the surgeons did not communicate? "I felt the need, I felt it, but I did not". REASONS FOR COMMUNICATION/NON-COMMUNICATION:

Because the rights of citizens, while ill, were at stake with questionable practices, some of which were attempted against the state of the art and against the rights of citizens while ill. E12 (12/03/ 2018).

Out of ethical obligation. When we are confronted with activities and performances that do not meet the standards, ahmmm, we must, and I think that in the first place, peers must call attention to them for investigation. E13 (09/03/2018).

Because they lacked the resources that prevented adequate treatment for patients. Fundamentally for that [ . . ] but there is another secondary factor, which is the issue of legal protection, too. E14 $(14 / 03 / 2018)$.

My patience basically ended, so I'm not for it. E5 (28/02/2018).

[...] For not having the courage to do that. Because going against a colleague is something that really [...] hmmm (pause) costs me! E15 (22/03/2018).

Because clearly the College cannot contain the information, and there would clearly be negative repercussions for me. E11 (08/03/2018).

I spoke with my superiors who said not to do it [ . . . E16 (14/03/2018).

\section{Category - Context and individual ethics}

RULES OF ECONOMIC CONSTRAINT - 17 say no; 8 do not know. PUBLIC/PRIVATE HOSPITAL - some answers are as follows:

In private hospitals, containment is less because the customer pays. (...) The SNS wants equal healthcare for everyone E6 (26/02/2018).

A certain surgical act whose recovery of the patient is much faster [...] the state, a public hospital, does not fall within the purview of its ministry to absent the patient. As the sick person's absenteeism does not fall within the purview of his ministry, it is the most economical. E17 (15/03/ 2018) 
EJMS

26,1

The difference is that in public hospitals, often, price counts as the only criterion, while in private hospitals, obviously the price is important - not least because the business that sells health will be bigger - but at the same time, there is the notion that the quality of the services provided must be guaranteed, as this is part of a basic commercial relationship that favours customers and which, by guaranteeing quality, makes them sought after. E11 (08/03/2018).

The private sector essentially seeks profit for profit [...] as long as the material is enough for [...] for the activity, even if it is not the best quality, but that ensures the lowest price [...] the private sector is there, who usually makes purchases of materials based on profit.

Economic power is very concentrated on the private side, and the private side may have other types of financing than the public side. Anyway, major surgery and high-definition surgery and high-tech surgery are not done privately! Despite these constraints, the public responds to this type of pathology. The most complex is not done in the private sector! E18 (20/03/2018).

\section{BENEFICIENCE AS A MEANS OF OBTAINING RESOURCES DENIED - 21 surgeons deny having lied}

Ask for surplus material and then leave it for another patient to follow [...] so that we have a means available for the patient to start treatment. E16 (14/03/2018).

Hyperbolise a clinical description to achieve it more easily. E11 (08/03/2018).

It is not lying! This act is not considered a lie to get some [...] some specific treatment for a patient who, due to misinterpretation, has been denied. E14 (23/02/2018).

\section{PROTOCOLS AND VITAL VARIABILITY - All meet vital variability:}

The protocols exist to have a guideline for the treatment of a patient. However, patients are not all the same, and there are particularities that compel us, hmmm, not to follow the protocol. E18(20/ 03/2018).

\section{THE BEST TREATMENT FOR THE HIGHEST NUMBER - 23 positives, with permission, as follows:}

I think that most of them have allowed us to treat patients, but [...]. it is not the excellency. E5 (28/02/2018).

\section{Category - Ethical decision-making INFLUENCE OF HUMAN RESOURCES DEPARTMENT (HRD) - Just one affirmative answer:}

To the extent that, for example, the definition of the workload that is assigned to the emergency department and that is withdrawn from our own department. Doctors have a workload defined by the board of directors, which is the hours that they are assigned to emergencies, which are not done in the surgery department. The surgery department is penalised, and the quality of care is penalised because these human resources are directed to the emergency services.

\section{INFLUENCE OF ETHICS COMMITTEE - two positive and four answers similar to the following:}

Unless I ask for the ethics committee's support and listen to it and then I make my decisions according to what their opinion is.

In addition to the interviews, journals from within the area demonstrate the concerns that general surgeons show both towards cost restraint and the need to remain up to date with 
regard to practices considered state of the art. This, in conjunction with technological innovation, is perceived as beneficial to patients, conveying a positive cost-benefit ratio after accounting for all the indirect costs.

Budgetary

restrictions

\section{Discussion and conclusions}

This research aimed to assess whether Portuguese general surgeons, guided by a code of ethics that represents itself as a pillar of their practice, maintain their best practices in the face of the economic restrictions to which they are subjected.

In regard to the first sub-question, "how do these restrictions interfere with the efficiency of surgeon choices?", interviewees explained that the crisis/recession continues to be felt, especially in terms of an urgent shortage of human resources, a lack of access to technological innovations with which they would better perform their activities and the training and remuneration of surgeons, which then leads to exhaustion and demotivation. Their best practices are affected by economic constraints in a number of ways, as their efficiency depends on the resources placed at their disposal; in addition, any shortcomings interfere with the good treatment of patients and correspondingly, surgeons often have to resort to the cancellation and/or postponement of surgeries. Regarding new technologies, the discussion between surgeons and surgeon-managers on the cost-benefit ratio for the acquisition of these technologies remains an ongoing issue. These doctors express an intrinsic responsibility towards budget management even though they are not professionally obliged to do so. This is expressed, for example, through concerns over acquisition costs of innovative technologies that enable improved surgical times and faster and better patient recovery.

Despite the conflict between the current economy and the leges artis, our findings point to the maintenance of individual ethics and these professionals not giving up on their freedom to exercise their clinical and ethical judgement.

Concerning the second question of this research, "do general surgeons apply their right to the conscientious clause whenever these restrictions conflict with their consciences?", there emerged a certain ambivalence in the attitudes of these professionals; approximately 50\% directly appeal to their right to the conscientious clause, while the other half refuses to operate on patients without the right conditions and instead transfer them to SNS tertiary hospitals, which have departments that are equipped with hardware and skills for more complex surgical operations. We may interpret such transfers as part of an indirect, undeclared conscientious clause.

Regarding the third research question, "does the surgeon communicate to the college any irregular situations caused by any constraints that lead to any incompetent attitudes or thirdparty infractions of rules of conduct?", the surgeons replied that the Portuguese College of Physicians is not perceived as the core body for reporting offences that might be resolved internally. The emphasis here is placed on perceptions not only about the difficulties inherent to such processes but also fears over post-process retaliation. The psychological cost of denouncing one's colleagues is too high, and thus, these cases are only rarely handled outside the hospital.

The fourth question, which seeks to understand whether there are differences in the containment rules prevailing in public and private institutions, received a unanimous answer from surgeons; both public and private hospitals have variable containment rules, and while the aim of the former is to treat everybody, while the latter seeks profit through quality and/or through price, technically demanding surgeries are still performed in public hospitals. There is a consensus around this issue that attributes responsibility to the SNS for treating all patients with fairness, while simultaneously minimising waste and not striving for profit.

Finally, this project sought to explore whether the HRD or the ethics committee (ESC) influence decision-making. Unanimity was achieved in the responses received; neither the 
EJMS

26,1

26

human resource department nor the ethics committee interferes in the ethical decisionmaking of these surgeons.

In the current study, Portuguese surgeons thus, expressed concerns over health economics and the consequences for their patients and concluded that the optimum SNS that was once provided is currently translated into a good standard of patient treatment. This institution is perceived more as a management board than as a health service supporting the population. While there is identification with the values of the SNS, the prevailing perceived reality does not align with those values.

Surgeons do not lie, but they always try to subliminally obtain the resources they need to treat their patients better. The vital variability of each patient constitutes a priority that surpasses the protocols in effect, even while the importance of these as guidelines for best practice is well and duly recognised. Regardless of the economic factors, there is the general recognition that all patients receive treatment, even if such treatment is not to the desired standard of excellence. While accepting these limitations, surgeons maintain and practice the deontological code of medicine and apply a Kantian ethic in regard to treating their patients, i.e. not as a means but as an end in itself.

We may, therefore, conclude that despite the pressures felt, surgeons, maintain the ethical and deontological principles of their profession with fair rules of orientation for those who choose to serve humankind by saving lives, although sometimes at a high cost.

This paper is a contribution to understanding the rules that restrain the activities of surgeons and in this sense is a study with possible practical and theoretical implications. It represents the sequency of Portuguese ethnographic studies in hospitals started by Graça Carapinheiro, followed by Helena Serra and Tiago Correia, to understand the mainstream of institutional relationships. Furthermore, it helps to analyse the ethical behaviour of surgeons in an environment of economic difficulties.

The importance of this study can be realised by its continuity. One of the authors is already implicated on a wider research to investigate the influence of the economic scarcity resources on general surgeons' ethical behaviours.

Politicians sometimes do not have a full understanding of the pressures that the medical profession faces in their day-to-day activities. Currently, with the addition of problems relate to COVID-19, politicians and populations seem to better understand the importance of the SNS. We hope that this understanding will be not only a conjectural moment.

\section{References}

Bardin, L. (2003). L'analyse de contenu, 11.a edição., Presses Universitaires de France.

Barros, N.F. \& Nunes, E.D. (2009). Sociologia, medicina e a construção da sociologia da saúde. Revista de Saúde Pública, 43(1), 169-175.

Brall, C., Schroeder-Back, P., \& Brand, H. (2016). The economic crisis and its ethical relevance for public health in Europe - an analysis in the perspective of the capability approach. Central European Journal of Public Health, 24(1), 3-8.

Carapinheiro, G. (2010). Equidade, cidadania e saúde: Apontamentos Para uma reflexão sociológica. Alicerces, 3(3), 57-64.

Correia, T. (2012). Medicina. O agir numa saúde em mudança, Lisboa: Editora Mundos Sociais.

Greenwood, M. (2002). Ethics and HRM: A review and conceptual analysis. Journal of Business Ethics, 36(3), 261-278.

Hortal, A. (2004). Ética general de las profesiones, Bilbao: Desclée de Brower.

Jennings, M. (2006). Seven signs of ethical collapse, New York, NY: St. Martin’s Press. 
Kohlberg, L. (1969). Stage and sequence: the cognitive-developmental approach to socialization. In Handbook of Socialization Theory and Research, ed., D. A. Goslin, Rand McNally, New York, 347-380.

Manuila, L., Manuila, A., Lewalle, P., \& Nicoulin, M. (2000). Dicionário médico, Lisbon: Climepsi Editores.

Neves, M.D.C.P. (2016). Ética: dos fundamentos às práticas, Lisboa: Edições 70.

Rawls, J. (2013). Uma teoria da justiça, Lisboa: Editorial Presença.

Rego, I., Russo, G., Gonçalves, L., Perelman, J., \& Pita Barros, P. (2017). A crise económica em médicos do serviço nacional de saúde: Estudo descritivo das suas percepções e reações em unidades de saúde na região da grande Lisboa. Acta Médica Portuguesa, 30(4), 263-272.

Sakellarides, C., Castelo Branco, L., Barbosa, P., \& Azevedo, H. (2014). The impact of the financial crisis on the health system and health in Portugal, Copenhagen: WHO Regional Office for Europe.

Santos, J. M. (2012). Introdução à ética, Lisbon: Sistema Solar.

Serra, H. (2008). Maus fígados: A construção social da tomada de decisão médica. Sociologia, Problemas e Práticas, 58, 47-70.

Torrington, D., Hall, L., Taylor, S., \& Atkinson, C. (2009). Fundamentals of human resource Management-Managing people at work, Harlow: Pearson Education.

Treviño, L. K. \& Nelson, A. K. (2011). Managing business ethics - straight talk about how to do it right, Hoboken: Wiley.

Yin, R. K. (2016). Pesquisa qualitativa do início ao fim, Porto Alegre: Penso.

\section{Further reading}

Associação Portuguesa de Bioética. (2017). Disponível em www.apbioetica.org/gca/index.php?id=147\& idbloco $=155$

Diário da República. (2016). Regulamento ${ }^{\circ} 707 / 2016$. Disponível em https:/dre.pt/home///dre/ 75007439/details/maximized?p_auth $=$ x9ZxiBJH\&serie $=$ II\&parte_filter $=33 \&$ dreId $=75007382$

Hospital de São João - Comissão de Ética. (2017). Disponível em http://portal-chsj.min-saude.pt/pages/62

Juramento de Hipócrates. (1983). Disponível em http://ordemdosmedicos.pt/wp-content/uploads/2017/ 08/Juramento_de_Hip\%C3\%B3crates.pdf

Lei de Bases da Saúde. (1990). Disponível em https://dre.pt/web/guest/pesquisa///search/574127/details/ normal?p_p_auth=zt2dAYbd

Machado MCS. Ética da decisão em saúde e terapêuticas inovadoras. (2012). Disponível em http://bit.ly/ $1 \mathrm{RJq} 8 \mathrm{Hc}$

OEDC. (2017). Health statistics 2017 (OECD.stat). Disponível em http://stats.oecd.org/index.aspx?r= 59781\&erroCode $=403 \&$ lastaction=login_submit

Plano Nacional de Saúde - DGS. (2017). Disponível em http://www2.insa.pt/sites/INSA/Portugues/ ComInf/Noticias/Documents/2015/Junho/PNS-2020.pdf

Retrato da Saúde em Portugal - Serviço Nacional de Saúde. (2021). Disponível em www.sns.gov.pt

Reunião Nacional de Comissões de Ética. (2021). Disponível em www.luzsaude.pt/media/2793589/ 1131_pt_p.pdf

Serviço Nacional de Saúde. (2016). Retrieved from www.sns.gov.pt/sns/redes-de-referenciacao-hospitalar

World Medical Association. (2018). Disponível em www.wma.net/what-we-do/medical-ethics/

\section{Corresponding author}

Rita Martins de Sousa can be contacted at: martins@iseg.ulisboa.pt 
EJMS

26,1

28

Individual ethics and deontology

Individual intervention for the common good

Context and individual ethics

Table A1.

Categories and subcategories
Ethical decisionmaking
Subcategory 1

Subcategory 2

Age

Number of years of activity

Public medicine/private medicinel public-private partnership Identification of values Health national service as an industry

The impact of the crisis

Constraints and good practices Responsibility for managing the budget

The efficiency depends on the allocation of resources

The cancelation/postponement of surgeries

Struggle between budget restrictions and leges artis

Curtail the freedom of clinicall ethicaljudgement

Economic restrictions and conscientious objections Referral due to lack of resources Report of infractions to the Ordem dos Médicos/other entity Reasons for report/non-report Rules of economic constraint Beneficence as a means of obtaining resources denied Protocols and vital variability The best treatment for the highest number

Influence of human resources department

Influence of ethics committee
Situations of crisis experienced Consequences

Interference in the treatment choice

Example of struggle

Public hospital/private hospital Ways of beneficence 


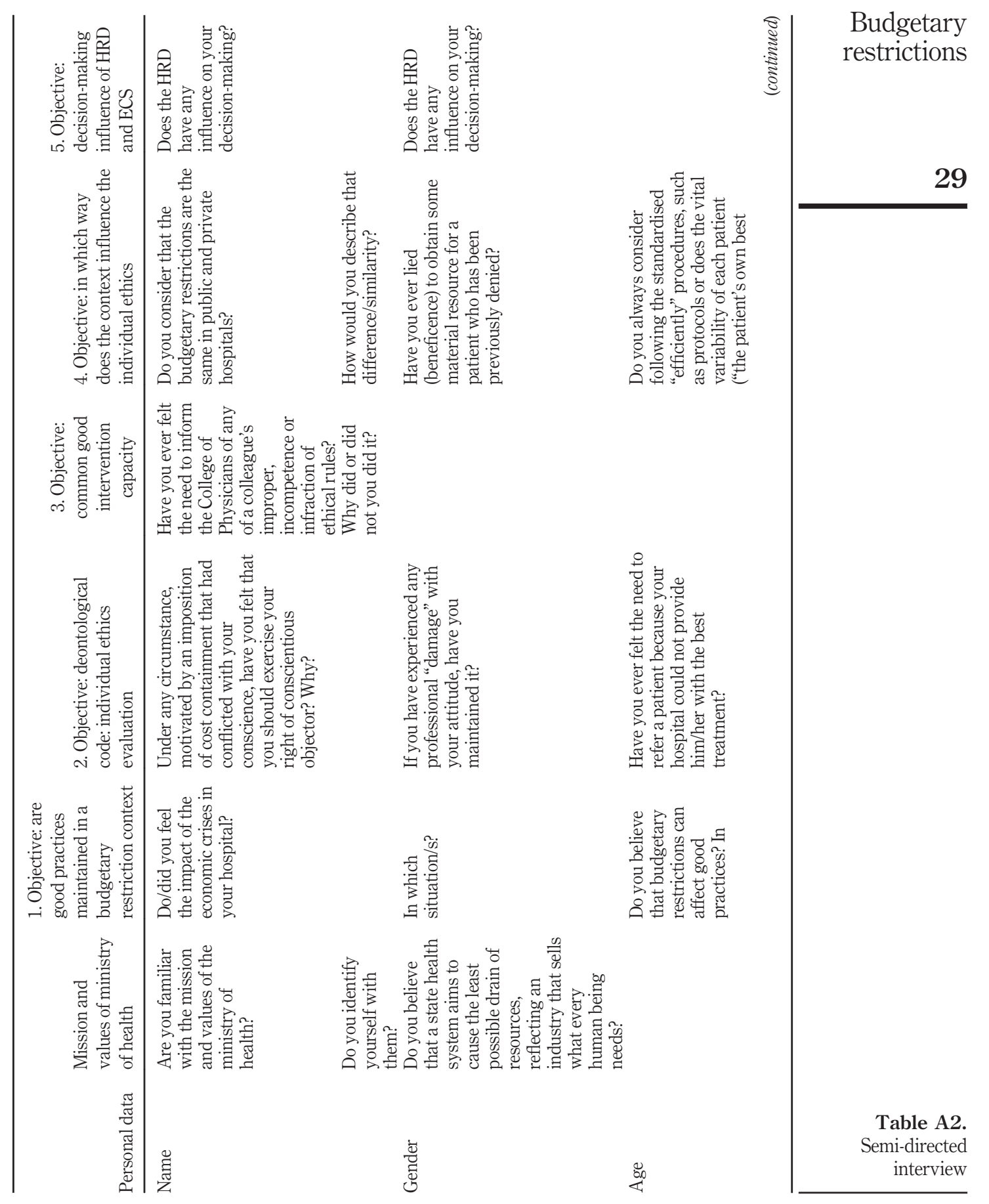




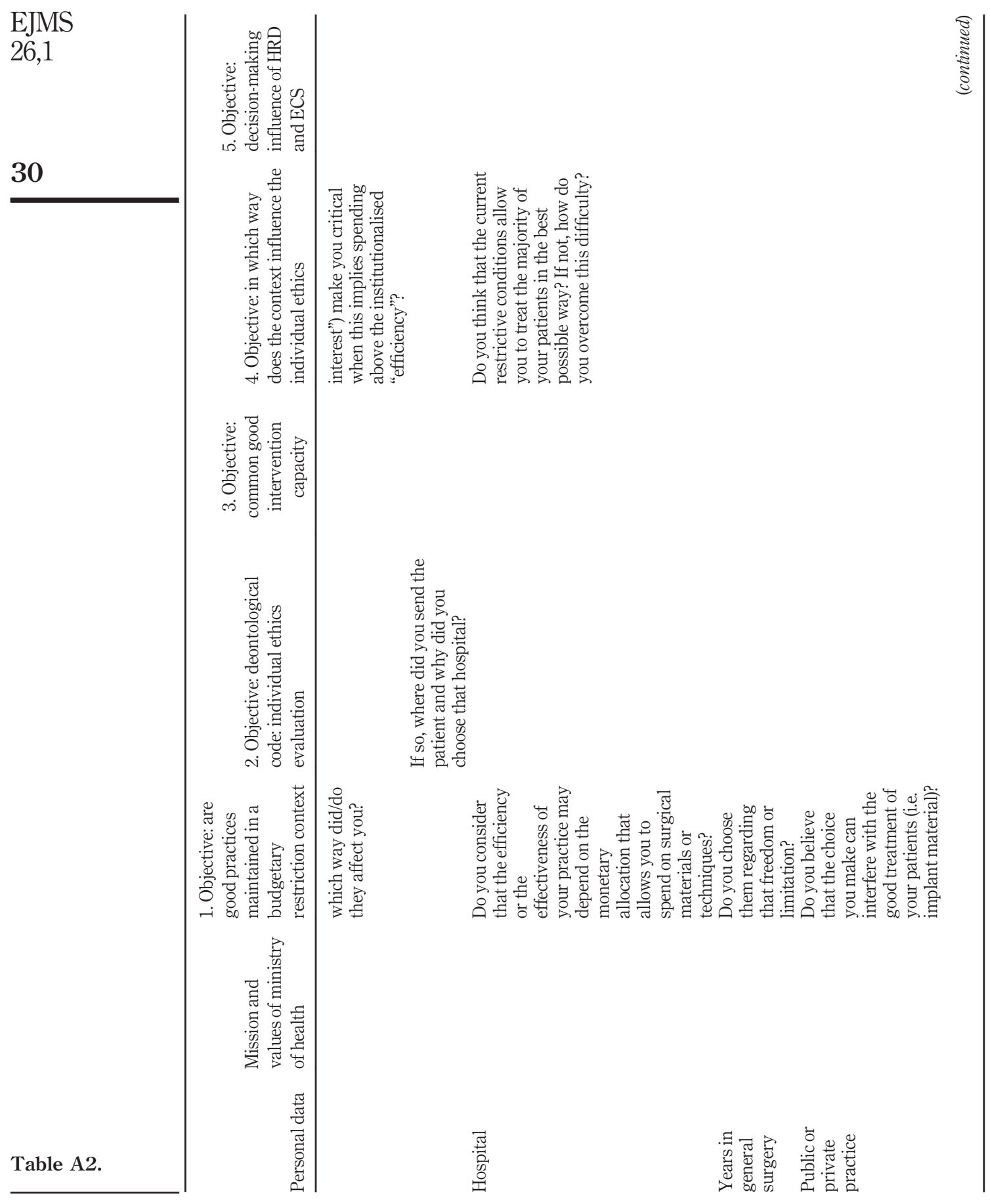




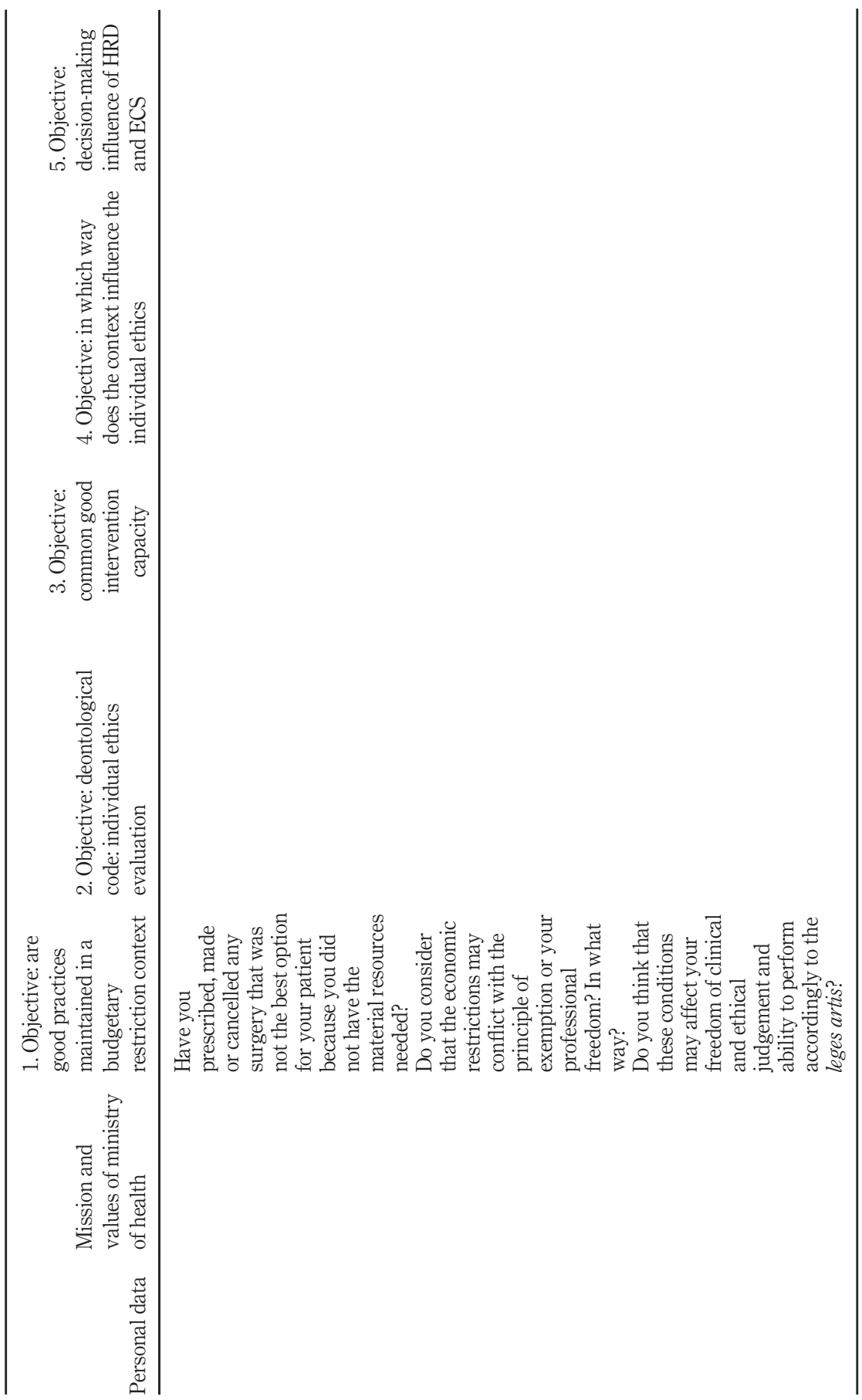

Budgetary restrictions

31

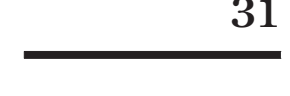

Table A2. 